\title{
TMT DMs final design and advanced prototyping results at Cilas
}

Jean-Christophe Sinquin, Arnaud Bastard, Corinne Boyer, Sébastien Cornette, Raphaël Cousty, et al.

Jean-Christophe Sinquin, Arnaud Bastard, Corinne Boyer, Sébastien Cornette, Raphaël Cousty, Brent Ellerbroek, Xavier Gilbert, Benoit Gourdet, Régis Grasser, Denis Groeninck, Claude Guillemard, Glen Herriot, Albert lannacone, Antoine Jeulin, Aurélien Moreau, Hubert Pagès, Lianqi Wang, "TMT DMs final design and advanced prototyping results at Cilas," Proc. SPIE 8447, Adaptive Optics Systems III, 844706 (13 September 2012); doi: 10.1117/12.925313

EPent: SPIE Astronomical Telescopes + Instrumentation, 2012, Amsterdam, Netherlands 


\title{
TMT DMs final design and advanced prototyping results at Cilas
}

\author{
Jean-Christophe Sinquin*a , Arnaud Bastard ${ }^{\mathrm{a}}$, Corinne Boyer ${ }^{\mathrm{b}}$, Sébastien Cornette ${ }^{\mathrm{a}}$, Raphaël Cousty ${ }^{\mathrm{a}}$, \\ Brent Ellerbroek $^{\mathrm{b}}$, Xavier Gilbert ${ }^{\mathrm{a}}$, Benoit Gourdet ${ }^{\mathrm{a}}$, Régis Grasser ${ }^{\mathrm{a}}$, Denis Groeninck ${ }^{\mathrm{a}}$, \\ Claude Guillemard ${ }^{\mathrm{a}}$, Glen Herriot ${ }^{\mathrm{c}}$, Albert Iannacone ${ }^{\mathrm{a}}$, Antoine Jeulin ${ }^{\mathrm{a}}$, Aurélien Moreau ${ }^{\mathrm{a}}$, \\ Hubert Pagès ${ }^{\mathrm{a}}$, Lianqi Wang ${ }^{\mathrm{b}}$ \\ ${ }^{\mathrm{a}}$ Cilas, 8 Avenue Buffon, Z.I. La Source, 45100 Orléans, France; ${ }^{\mathrm{b}}$ TMT Observatory Corporation, \\ 1200 East California Blvd., M/C 102-8, Pasadena CA 91125, USA; ${ }^{\circ}$ Herzberg Institute of \\ Astrophysics NRCC, 5071 W. Saanich Road, Victoria BC V9E 2E7, Canada
}

\begin{abstract}
In order to prepare for the construction phase of the two Deformable Mirrors (DMs), which will be used in the Thirty Meter Telescope (TMT) first light Adaptive Optics (AO) system, Cilas has advanced the design of these two large size piezo DMs and has manufactured and tested a scaled demonstration prototype. The work done allowed significant reduction of the risks related to the demanding specifications of the TMT DMs; the main issues were: (i) Large pupil (up to $370 \mathrm{~mm}$ ) and high order (up to $76 \times 76$ ); (ii) Relatively low operational temperature (DMs working at $-30^{\circ} \mathrm{C}$ ); (iii) New piezo material. It is important to develop such a prototype to take into account these three specifications all together (dimension, low temperature and new piezo material). The new prototype is a $6 \times 60$ actuators and has the same characteristics as the future TMT DMs. In this paper, we give the conclusions of the work through the presentation of the following items: (i) Design and finite element analysis of the two DMs and prototype; (ii) Test results obtained with the prototype with validation of the finite element analysis and compliance with the TMT AO specifications; (iii) Special focus on thermal behavior, actuator reliability and shape at rest stability.
\end{abstract}

Keywords: adaptive optics, deformable mirror, stack array mirror, piezostack actuator, SAM

\section{INTRODUCTION}

The first light facility AO system for TMT is the Narrow Field Infra-Red AO System (NFIRAOS); this Multiconjugate Adaptive Optics System will provide diffraction-limited performance in the J, H, and K bands over 17-30 arc sec diameter fields ${ }^{1,6}$. This will be accomplished using, in particular, two deformable mirrors conjugated to 0 and $11.2 \mathrm{~km}$ altitude. The first one called DM0 optically conjugated to ground is mounted on a Tip-Tilt Stage (TTS) and shows 3125 actuators (63x63 array); the second one called DM11.2 shows 4548 actuators (76x76 array). These DMs are dedicated to:

- High-bandwidth, high-order wavefront correction for errors associated with both atmospheric turbulence and optical aberrations present in the telescope, the science instrument and the Adaptive Optics system itself;

- High-bandwidth, low-stroke tip-tilt correction for errors associated with atmospheric turbulence and telescope vibration;

- Tip-tilt anisoplanatism correction for the differential tip/tilt between the natural guide star(s) and the science field.

*sinquin@cilas.com; http://www.cilas.com 
The work done at Cilas and presented hereafter consisted in two main phases in parallel:

- $\quad$ design of the two NFIRAOS DMs;

- design, manufacturing and test of a 6 x60 subscale prototype.

The aim of the prototyping phase was to validate design choices and to mitigate identified risks. In particular, following items have been studied:

- $\quad$ Large pupil (up to $370 \mathrm{~mm}$ ) and high order (up to 76x76 array)

- Relatively low operational temperature (DMs working at $-30^{\circ} \mathrm{C}$ )

- Finite element model (FEM) for thermo mechanical, static and dynamical behavior

- Manufacturing processes

- New piezo material

- Actuator electrical behavior (electrical properties and reliability)

- $\quad$ Shape at rest stability

Note that the 6x60 subscale prototype is sufficient to address properly the large pupil issue since measured results can be extrapolated easily to final dimensions with the help of FEM.

\section{DEFORMABLE MIRRORS SPECIFICATIONS}

DMs main requirements are summarized on Table 1. These requirements are also compared to Cilas piezo array DMs "usual" characteristics or capabilities.

Table 1. NFIRAOS deformable mirrors main specifications and comparison with Cilas technology.

\begin{tabular}{|c|c|c|c|}
\hline Parameter & DM0 & DM11.2 & Cilas piezo array technology \\
\hline $\begin{array}{l}\text { Number of useful } \\
\text { actuators }\end{array}$ & 3125 (63x63 array) & 4548 (76x76 array) & Up to several thousands \\
\hline Clear aperture & Ellipse $301 \mathrm{~mm}$ x $313 \mathrm{~mm}$ & Ellipse $366 \mathrm{~mm} \times 374.5 \mathrm{~mm}$ & $\begin{array}{l}\text { Up to } 500 \mathrm{~mm} \text { diameter (with same } \\
\text { technology) - circular or elliptical aperture }\end{array}$ \\
\hline Actuator spacing & $5 \mathrm{~mm} \times 5.148 \mathrm{~mm}$ & $5 \mathrm{~mm} \times 5.077 \mathrm{~mm}$ & $\begin{array}{l}\text { Standard spacing values are: } \\
3.5 \mathrm{~mm}, 5 \mathrm{~mm}, 7 \mathrm{~mm}, 10 \mathrm{~mm}, 14 \mathrm{~mm} \ldots\end{array}$ \\
\hline Stroke (mechanical) & $\geq 10 \mu \mathrm{m}$ PV after flattening & $\geq 10 \mu \mathrm{m}$ PV after flattening & $\begin{array}{l}\text { Standard stroke } \geq 10 \mu \mathrm{m} \text { PV for } 5 \mathrm{~mm} \\
\text { spacing }\end{array}$ \\
\hline Mechanical coupling & $30 \% \pm 2.5 \%$ & $30 \% \pm 2.5 \%$ & $\begin{array}{l}25 \text { to } 30 \% \text { (according to the need in order } \\
\text { to obtain the best fitting error) }\end{array}$ \\
\hline $\begin{array}{l}\text { Inter-actuator stroke } \\
\text { (mechanical) }\end{array}$ & $1.9 \mu \mathrm{m}$ & $1.9 \mu \mathrm{m}$ & $\begin{array}{l}30 \text { to } 40 \% \text { of the max stroke PV } \\
\text { (according to mechanical coupling value) }\end{array}$ \\
\hline $\begin{array}{l}\text { Actuator first natural } \\
\text { frequency }\end{array}$ & $>10 \mathrm{kHz}$ & $>10 \mathrm{kHz}$ & 10 to $20 \mathrm{kHz}$ \\
\hline $\begin{array}{l}\text { Optical quality (once } \\
\text { the mirror flattened) }\end{array}$ & $\begin{array}{l}<30 \mathrm{~nm} \text { rms WFE } \\
(\text { goal }<20 \mathrm{~nm} \text { rms WFE) }\end{array}$ & $\begin{array}{l}<30 \mathrm{~nm} \mathrm{rms} \mathrm{WFE} \\
(\text { goal }<20 \mathrm{~nm} \text { rms WFE) }\end{array}$ & $\begin{array}{l}<20 \mathrm{~nm} \text { rms WFE (polishing done at the } \\
\text { end of manufacturing) }\end{array}$ \\
\hline Optical surface shape & Flat & Flat & $\begin{array}{l}\text { Flat, concave or convex (aspherical shape } \\
\text { is also possible) }\end{array}$ \\
\hline Hysteresis & $\begin{array}{l}<10 \% \\
(\text { goal }<5 \%)\end{array}$ & $\begin{array}{l}<10 \% \\
(\text { goal }<5 \%)\end{array}$ & $\begin{array}{l}<5 \% \text { (for full stroke), thanks to piezo } \\
\text { material }\end{array}$ \\
\hline Dissipated power & $<2 \mathrm{~W}$ & $<3 \mathrm{~W}$ & $\begin{array}{l}\text { Very low at mirror level, thanks to } \\
\text { capacitive principle }\end{array}$ \\
\hline Control voltage range & $\pm 400 \mathrm{~V}$ & $\pm 400 \mathrm{~V}$ & $\pm 400 \mathrm{~V}$ \\
\hline $\begin{array}{l}\text { Operating } \\
\text { temperature }\end{array}$ & $-30^{\circ} \mathrm{C}$ to $25^{\circ} \mathrm{C}$ & $-30^{\circ} \mathrm{C}$ to $25^{\circ} \mathrm{C}$ & $\begin{array}{l}\text { Very low temperature dependence, thanks } \\
\text { to materials choice }\end{array}$ \\
\hline
\end{tabular}

Proper adaptation of piezo array technology to NFIRAOS is clearly visible on this comparison table. 


\section{DESIGN AND FINITE ELEMENT ANALYSIS}

\subsection{General}

NFIRAOS DMs are therefore based on Cilas piezo array technology. This technology offers stabilized and reliable solutions for DMs with large number of actuators at high density. Classically it includes three main components, which are:

- The deformable optical plate,

- The actuator array,

- A rigid baseplate.

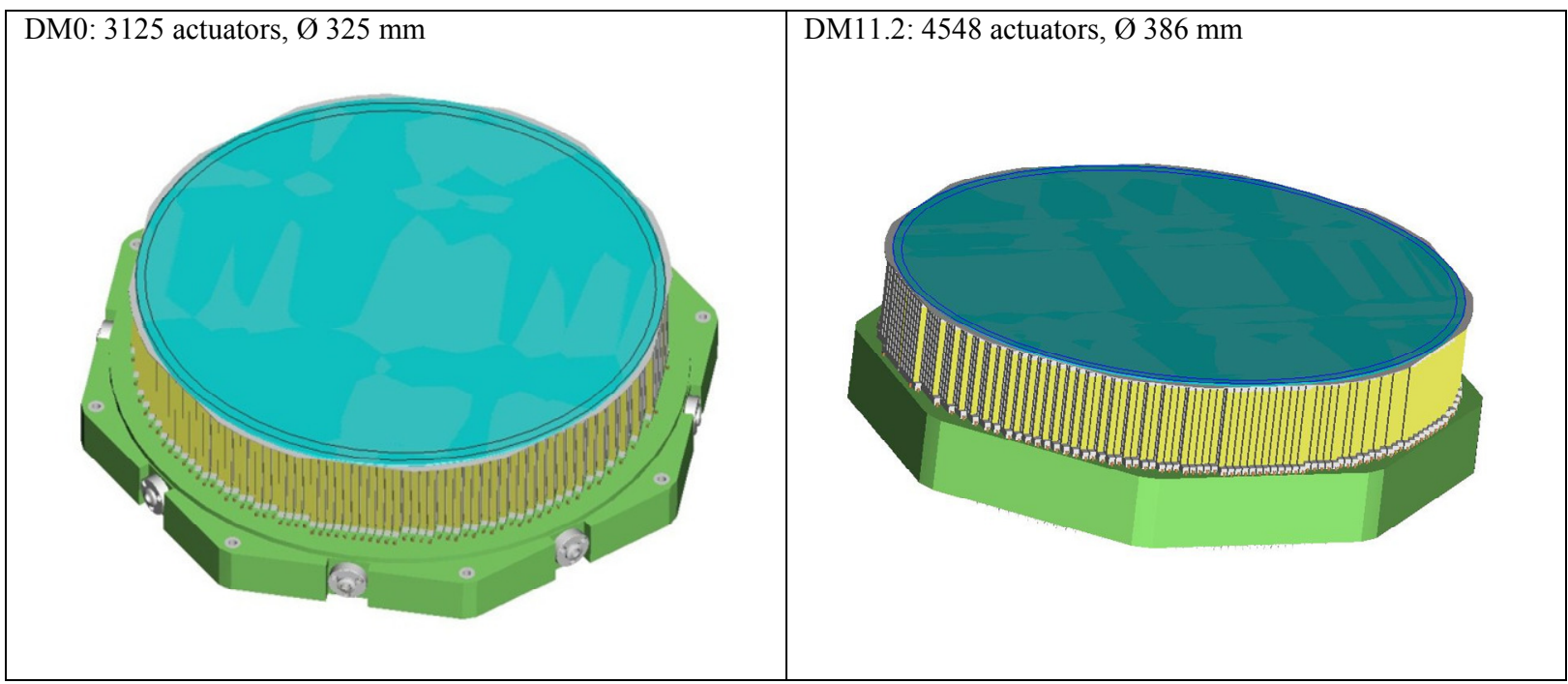

Figure 1. Overview of NFIRAOS DMs design.

In order to mitigate identified risks, a prototype has been designed for addressing large dimension, low temperature and new piezo issues. The functional scaled Demonstration Prototype (DP) includes 360 operational actuators. The design of these actuators is the same as those of DM0 and DM11.2. Its larger dimension is close to DM0 diameter. All constituting materials are the same as those of DMs. The mechanical, thermal and electrical behavior of the DP is therefore fully representative of DM0 and DM11.2 behavior.

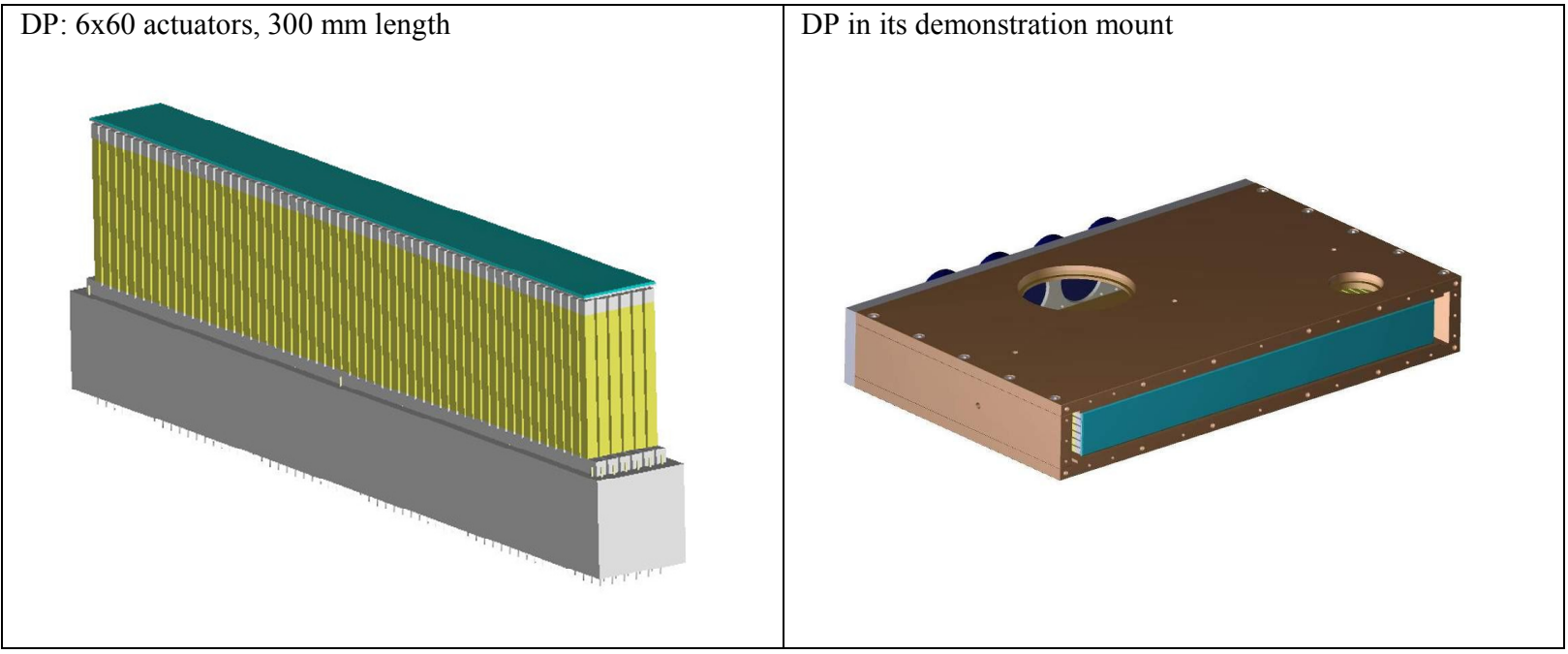

Figure 2. Overview of DP design. 


\subsection{Influence function and strokes}

Theoretical influence functions of DMs are determined by mechanical Finite Element Models (FEM). These models allow an evaluation of the stroke ability, the inter-actuator stroke ability and the mechanical coupling between actuators. These parameters are closely linked to the length of the actuators and the thickness of the optical plate. A specific dimensioning was done in order to reach the expected performance.

Thanks to the chosen design, the stroke ability of DM0, DM11.2 and the scaled DP will be equivalent, thus the experimental test results of the DP fully demonstrate the performance of the final DMs.

At low temperature, we expect a very low reduction of the piezo material charge coefficient, which means that the stroke ability at $-30^{\circ} \mathrm{C}$ is expected to be very close to the one obtained at $+20^{\circ} \mathrm{C}$. Theoretical mechanical stroke is:

$\geq 14 \mu \mathrm{m}$ PV@ $+20^{\circ} \mathrm{C}$

$\geq 13.5 \mu \mathrm{m}$ PV@ $-30^{\circ} \mathrm{C}$

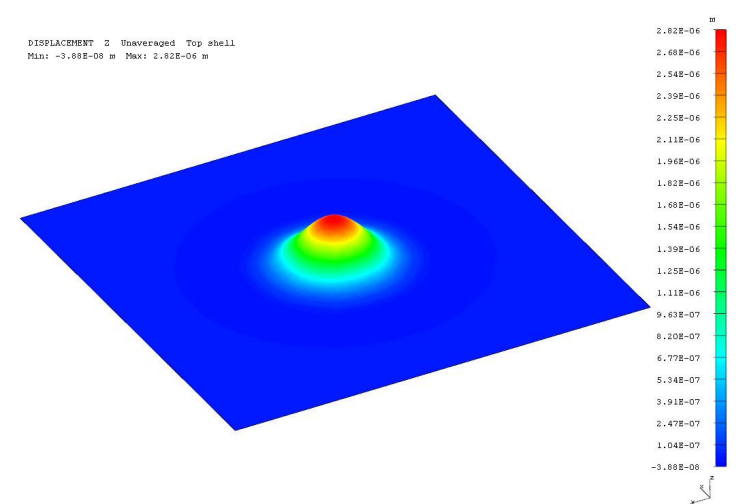

Figure 3. Single stroke of $2.8 \mu \mathrm{m}$ obtained at $+20^{\circ} \mathrm{C}$ when one actuator is driven at $+400 \mathrm{~V}$.

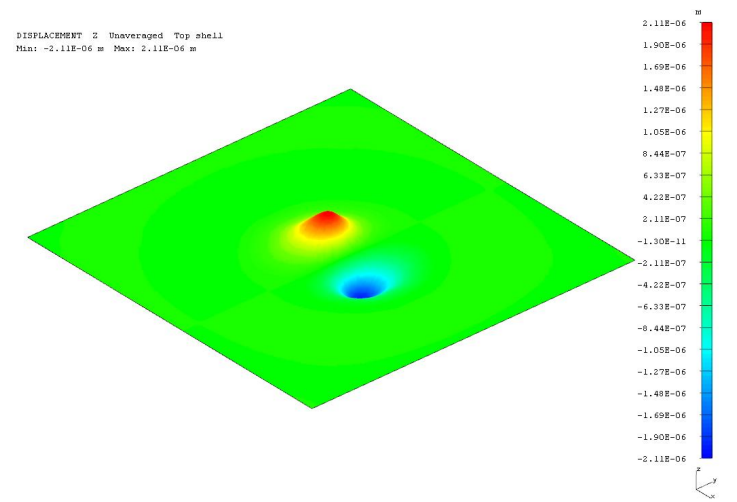

Figure 4. Inter-actuator stroke of $4.2 \mu \mathrm{m} \mathrm{PV}$ obtained when one actuator is driven at $+400 \mathrm{~V}$ and its neighbor at $-400 \mathrm{~V}$.

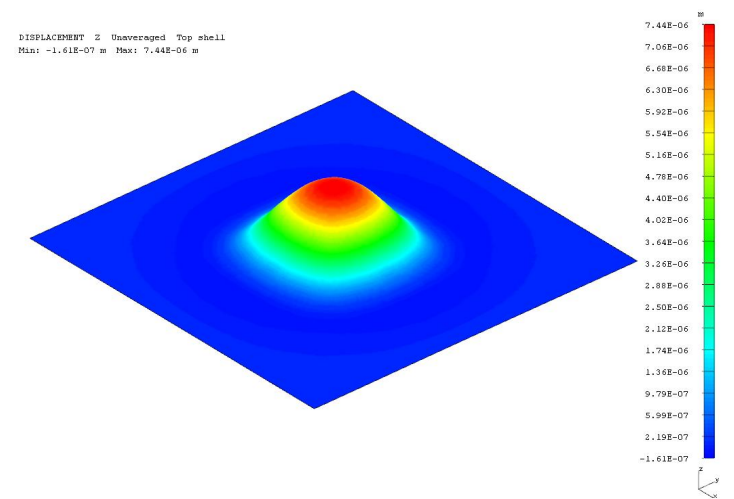

Figure 5. Maximum stroke of $7.4 \mu \mathrm{m}$ obtained when $3 \times 3$ actuators are driven at $+400 \mathrm{~V}$. 


\subsection{Stroke ability and optical quality after flattening}

Most of the actuator stroke will be used to compensate for the turbulence spectrum; however, a fraction of the actuator stroke will be necessary to flatten the mirror in order to correct the mirror intrinsic defects, which are:

- Polishing errors,

- Evolution of shape vs. time (mainly due to ageing of the glue),

- Evolution of shape vs. temperature.

These three contributors, which are commented hereafter, are taken into account to obtain the results given in Table 2:

Table 2. Theoretical stroke performances and optical quality once mirror flattened.

\begin{tabular}{|l|l|l|}
\hline \multicolumn{1}{|c|}{ Parameter } & \multicolumn{1}{c|}{ a $\mathbf{+ 2 0}^{\circ} \mathbf{C}$} & $\geq 9.5 \mu \mathrm{m} \mathrm{PV}$ \\
\hline Stroke (mechanical) & $\geq 10 \mu \mathrm{m} \mathrm{PV}$ & $5.4 \mu \mathrm{m} \mathrm{PV}$ \\
\hline $\begin{array}{l}\text { Single stroke } \\
\text { (mechanical) }\end{array}$ & $5.6 \mu \mathrm{m} \mathrm{PV}$ & $29 \%$ \\
\hline Mechanical coupling & $29 \%$ & $4.0 \mu \mathrm{m}$ \\
\hline $\begin{array}{l}\text { Inter-actuator stroke } \\
\text { (mechanical) }\end{array}$ & $4.2 \mu \mathrm{m}$ & $<22 \mathrm{~nm} \mathrm{rms} \mathrm{WFE}$ \\
\hline Optical quality & $<20 \mathrm{~nm} \mathrm{rms} \mathrm{WFE}$ & \\
\hline
\end{tabular}

\section{Polishing errors}

From return of experience on previous polishing, for piezo array mirrors showing such range of actuator spacing, the residual error is estimated at $20 \mathrm{~nm}$ rms wavefront.

\section{Evolution of shape vs. time}

NFIRAOS DMs design and manufacturing processes rely on the technical improvements carried out to control and to limit the evolution of shape of the mirror at rest vs. time. These improvements have been implemented and successfully qualified on other $\mathrm{DMs}^{2}$. An estimated residual error for this evolution is $8 \mathrm{~nm}$ rms wavefront, to be confirmed with measurements vs. time on DP.

\section{Evolution of shape vs. temperature}

In addition to the generic improvements already validated, specific studies were needed for NFIRAOS DMs due to the large dimension of the mirrors (pupil up to $370 \mathrm{~mm}$ ) and the low operating temperature $\left(-30^{\circ} \mathrm{C}\right)$.

Thanks to Cilas piezo technology, the internal thermal dissipation of DM is negligible and thus the operation of the mirror does not generate any thermal gradients or spurious deformation of its optical surface.

However, piezo DMs are made of several types of materials (piezo material, glass, metal, ceramic and glue) and, of course, the choice of each material for a large DM working at low temperature has a major impact on the DM performance.

For the NFIRAOS DMs, we focused especially on the homogeneity of all the coefficients of thermal expansion (CTE) between the different materials in order to reach the optimal performance at low temperature. For the dimensioning, Finite Element Analysis (FEA) was used to evaluate the effect of the thermal deformation.

Following the FEA, final references of materials used for NFIRAOS DMs are slightly different from the ones classically used on other Cilas DMs. These materials ensure a very low effect of temperature on DM performance. 


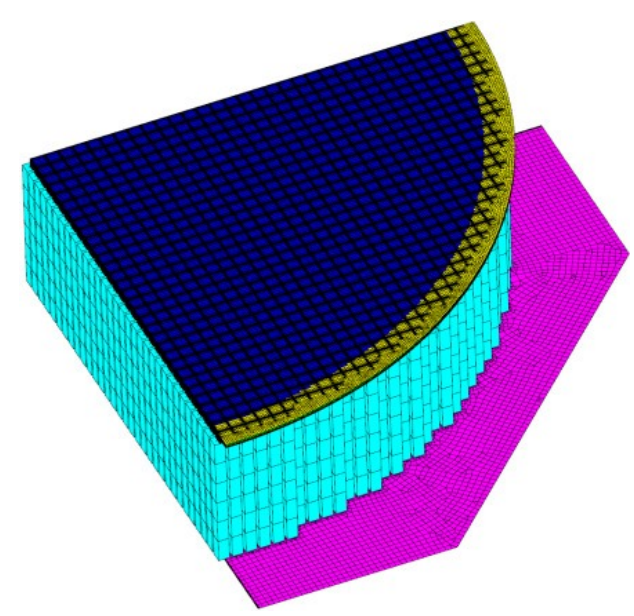

Figure 6. Thermo-mechanical FEM of DM0 (one quarter represented on the figure).

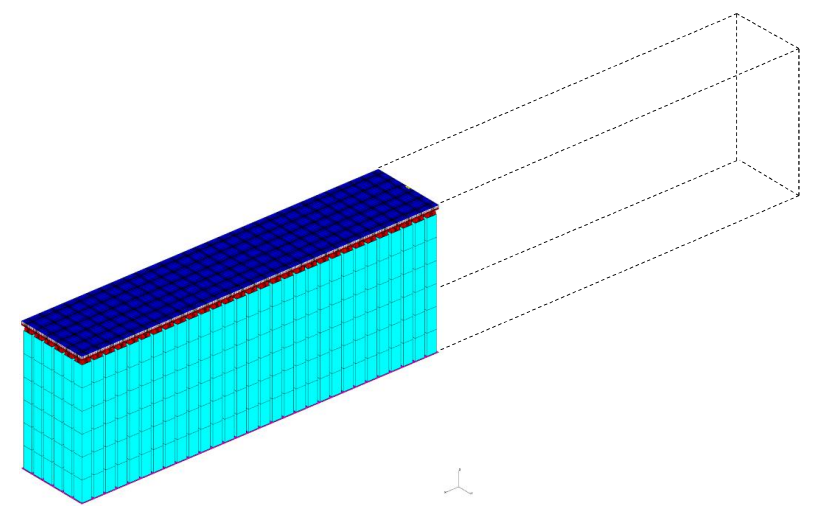

Figure 7. Thermo-mechanical FEM of DP (one half represented on the figure).

In parallel with the intrinsic design of the DMs, the dimensioning of the mechanical interfaces between each DM and its mounting structure is also very important in order to ensure a low deformation of the optical surface. Interfaces are different for DM0 and for DM11.2 but both of them are designed to compensate for the differential expansion between the DM and the mounting structure.

DM11.2 will be integrated in a fixed mounting structure with the help of ball plungers made of Delrin ball and steel spring.

DM0 will be integrated in in a tip-tilt stage (already manufactured, qualified and delivered to TMT ${ }^{3}$ ), see Figure 8 . The DM will be held by 8 flexible blades that compensate for the thermal expansion between the DM base plate and the tiptilt structure (see Figure 9). The dimensioning of this interface is more restricting than the one of DM11.2 because it must be, on one hand, soft enough for thermo-mechanical reasons and, on the other hand, stiff enough for dynamical reasons. 


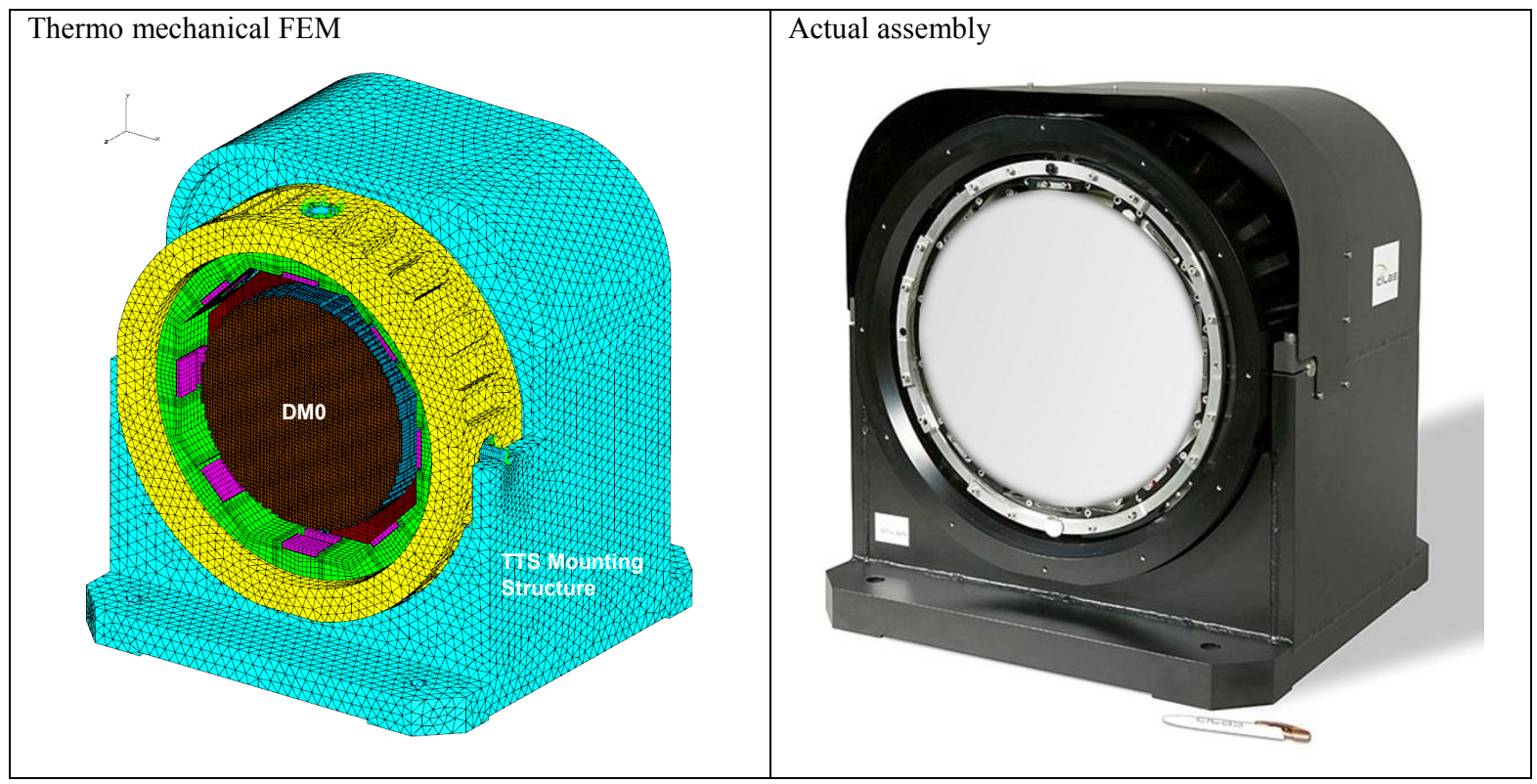

Figure 8. DM0 Tip-Tilt Stage.

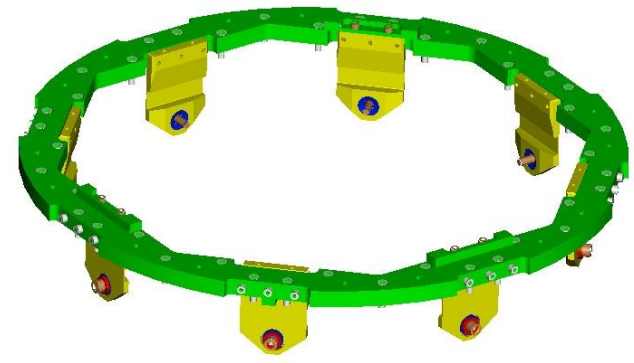

Figure 9. DM0 mechanical interface with flexible blades.

Focusing on the example of DM0, with the help of FEA, we obtained the following results ${ }^{4}$ (see Figure 10).

- Low order deformation of the optical surface:

$\leq 150 \mathrm{~nm}$ PV mechanical before flattening (mainly curvature)

- High order deformation:

$\leq 11 \mathrm{~nm}$ rms mechanical before flattening,

$\leq 1 \mathrm{~nm}$ rms mechanical after flattening (i.e. $2 \mathrm{~nm}$ rms wavefront).
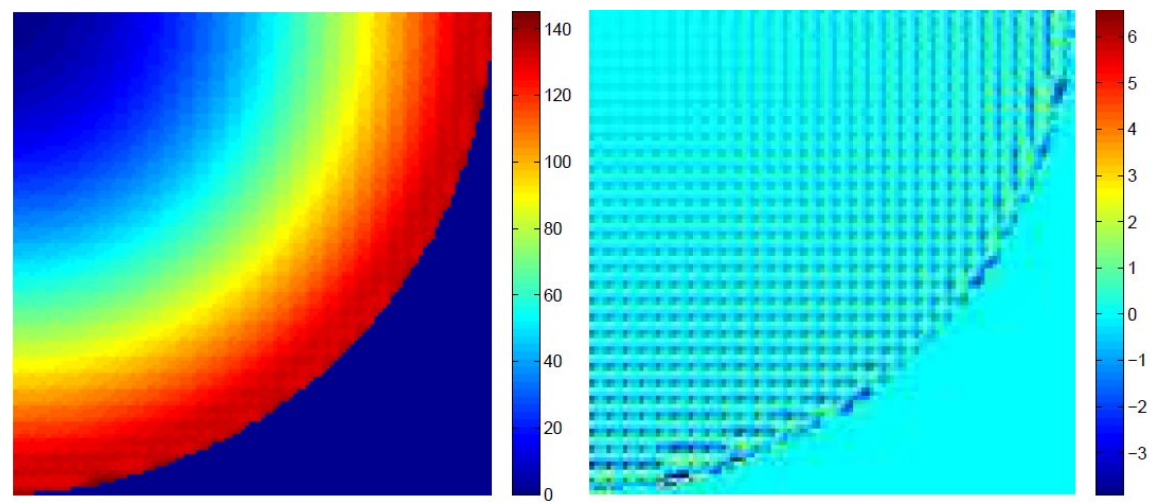

Figure 10. Shape of DM0 optical surface $@-30^{\circ} \mathrm{C}$ before (left) and after (right) flattening. 


\subsection{Dynamical behavior}

A modal analysis has been carried out using FEM to evaluate the dynamical behavior of DM0 and DM11.2. Theoretical results summarized in Table 3 show that the DM eigen modes should not disturb the performance of the DM in operation for the operating frequency range $(<1200 \mathrm{~Hz})$.

Table 3. DM modal analysis.

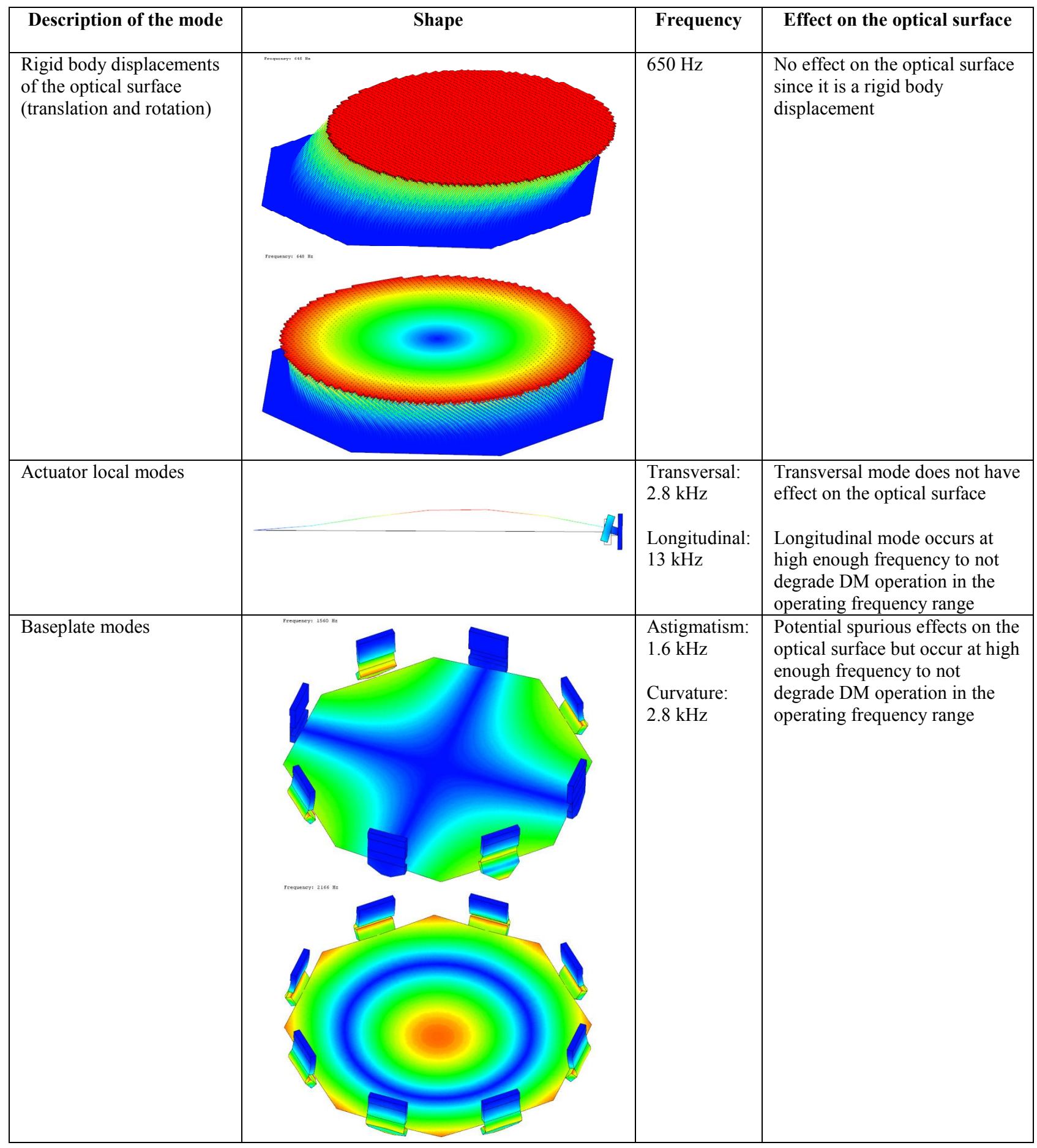




\section{TEST RESULTS}

Two series of test have been done. A first set of test allowed a verification of actuator main characteristics before assembling the array. In addition, accelerated ageing test and electrical breakdown test have also been conducted on actuator lines. A second set of test allowed a qualification of the assembled demonstration prototype.

\subsection{Test on actuator lines}

\section{Non-destructive testing}

Non-destructive testing of performance has been done on actuator lines (see one line on Figure 11).
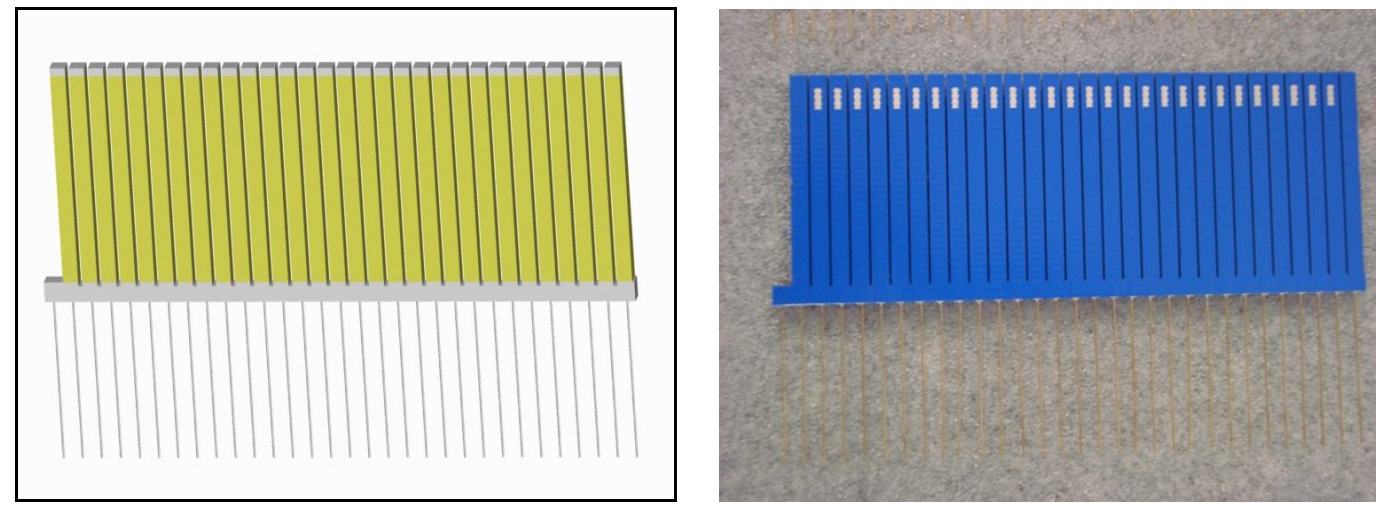

Figure 11. Image of the design (left) and photograph (right) of an actuator line: 30 actuators and contacting pins are visible two lines are needed to cover overall length of DP.

Main measured results are presented on Table 4. These results are compared to theoretical or expected values.

Table 4. Actuator line parameters measured values compared to theoretical values.

\begin{tabular}{|c|c|c|c|}
\hline Parameter & Measured on actuator line & Theoretical value & Comment \\
\hline Stroke at $20^{\circ} \mathrm{C}$ & $19 \mu \mathrm{m} \mathrm{PV}$ & $\geq 14 \mu \mathrm{m}$ PV & $\begin{array}{l}\text { Measured free stroke is always } \\
\text { somewhat higher than final stroke }\end{array}$ \\
\hline Stroke at $-30^{\circ} \mathrm{C}$ & $19 \mu \mathrm{m}$ PV - see Figure 12 & $\geq 13.5 \mu \mathrm{m} \mathrm{PV}$ & $\begin{array}{l}\text { Low variation of piezo material } \\
\text { property, as expected }\end{array}$ \\
\hline Frequency response & $\begin{array}{l}\text { No spurious mode below } \\
3 \mathrm{kHz}-\text { see Figure } 12 \\
\text { Resonance at } 13 \mathrm{kHz}\end{array}$ & $\begin{array}{l}\text { Resonance at } 13 \mathrm{kHz} \\
\text { (actuator longitudinal mode) }\end{array}$ & $\begin{array}{l}\text { Flat frequency response for gain and } \\
\text { phase in }[0 \mathrm{kHz}-3 \mathrm{kHz}] \text { range }\end{array}$ \\
\hline Hysteresis at $20^{\circ} \mathrm{C}$ & $\approx 3 \%$ & $\begin{array}{l}<5 \% \\
\text { (piezo material property) }\end{array}$ & \\
\hline Hysteresis at $-30^{\circ} \mathrm{C}$ & $\approx 5 \%-$ see Figure 12 & $\approx 5 \%$ & $\begin{array}{l}\text { Low variation of piezo material } \\
\text { property, as expected }\end{array}$ \\
\hline
\end{tabular}



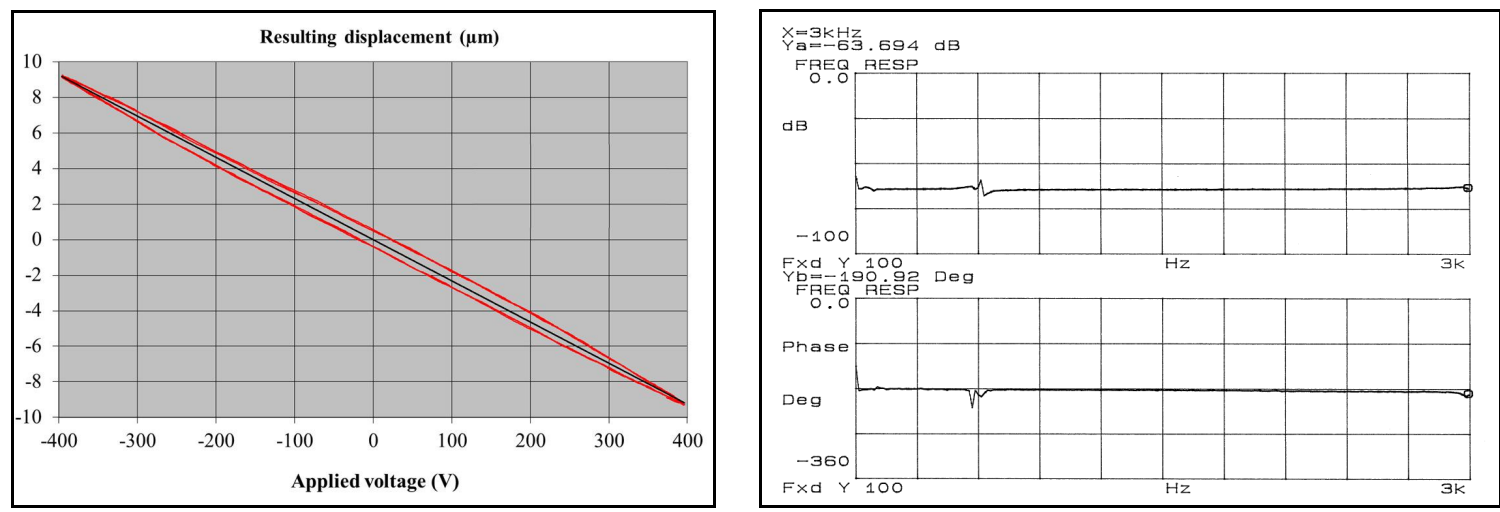

Figure 12. Measured stroke and hysteresis (left) and frequency response (left) for an actuator.

We see on Table 4 and Figure 12 that actuator line actual behavior is well within expected one.

\section{Destructive testing}

Accelerated ageing test and electrical breakdown test have been done on additional actuator lines. Main results are presented on Table 5 . These results are compared to values already obtained on other actuator lines ${ }^{2}$.

Table 5. Actuator line accelerated ageing and electrical breakdown test results.

\begin{tabular}{|c|c|c|c|}
\hline Test description & $\begin{array}{l}\text { Measured on actuator } \\
\text { lines and samples }\end{array}$ & Return of experience & Comment \\
\hline $\begin{array}{l}\text { Accelerated ageing under } \\
\text { following conditions: } \\
\text { Temperature }=85^{\circ} \mathrm{C} \\
\text { Humidity }=85 \% \mathrm{RH} \\
\text { Voltage }=400 \mathrm{~V}\end{array}$ & $\begin{array}{l}\text { - Electrical contacting: } \\
102 \text { hours without failure* } \\
\text { - Short circuit: } \\
14 \text { hours without failure* }\end{array}$ & $\begin{array}{l}\text { Time without failure } \\
>50 \text { hours }\end{array}$ & $\begin{array}{l}\text { In accordance to Cilas current model of } \\
\text { temporal acceleration factors }{ }^{2}, 50 \text { hours } \\
\text { without failure under ageing conditions } \\
\text { allows a theoretical lifetime in operational } \\
\text { conditions much larger than } 10 \text { years }\end{array}$ \\
\hline Electrical breakdown test & $\begin{array}{l}\text { Voltage for short circuit } \\
=1980 \mathrm{~V}\end{array}$ & $\begin{array}{l}\text { Voltage for short circuit } \\
=1800 \mathrm{~V}\end{array}$ & $\begin{array}{l}1800 \mathrm{~V}=2 * \mathrm{U}+1000 \mathrm{~V} \text { allows excellent } \\
\text { safety margin from standard rule on } \\
\text { electrical testing }\end{array}$ \\
\hline
\end{tabular}

*Partial result since no failure has been encountered.

Potential actuator line reliability is within expected one, from return of experience. Accelerated ageing tests are continuing. 
4.2 Test on prototype

Qualification testing has been conducted on DP (see Figure 13).
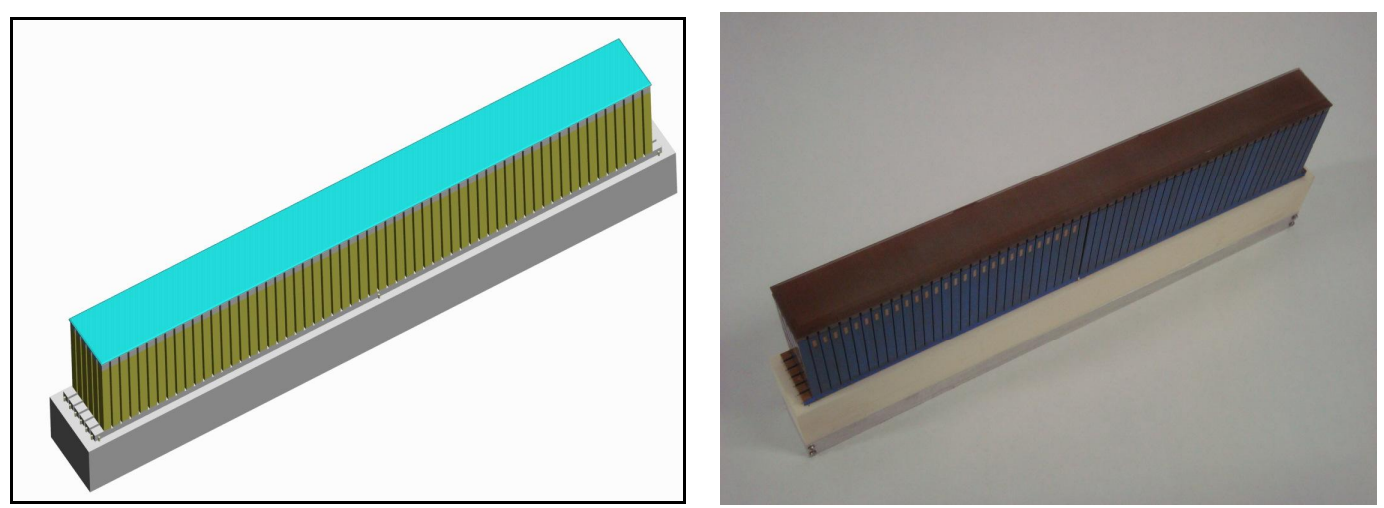

Figure 13. Image of DP design (left) and photograph of manufactured DP (right) - brown aspect of optical surface is due to color of glue visible through glass part of optical head.

\section{Test at ambient $\left(20^{\circ} \mathrm{C}\right)$}

Main measured results are presented on Table 6. These results are compared to theoretical or expected values.

Table 6. DP parameters measured values at $20^{\circ} \mathrm{C}$ compared to theoretical values.

\begin{tabular}{|l|l|l|l|}
\hline \multicolumn{1}{|c|}{ Parameter } & Measured on DP & Theoretical value & Comment \\
\hline $\begin{array}{l}\text { Stroke before } \\
\text { flattening }\end{array}$ & $16 \mu \mathrm{m} \mathrm{PV}$ & $\geq 14 \mu \mathrm{m} \mathrm{PV}$ & Value obtained when 3x3 actuators are driven at $+/-400 \mathrm{~V}$ \\
\hline Single stroke & $7 \mu \mathrm{m}$ PV & $5.6 \mu \mathrm{m} \mathrm{PV}$ & Value obtained when 1 actuators is driven at $+/-400 \mathrm{~V}$ \\
\hline Mechanical coupling & $\sim 25 \%$ & $29 \%$ & $\begin{array}{l}\text { This value can be easily corrected on future DMs by } \\
\text { adjustment of optical plate thickness }\end{array}$ \\
\hline Inter-actuator stroke & $4.8 \mu \mathrm{m}$ & $13 \mathrm{kHz}$ & $\begin{array}{l}\text { Value obtained when 1 actuator is driven at }+400 \mathrm{~V} \text { and } \\
\text { its neighbor at }-400 \mathrm{~V}\end{array}$ \\
\hline $\begin{array}{l}\text { Actuator main natural } \\
\text { frequency }\end{array}$ & $\mathrm{NA} *$ & $\begin{array}{l}\text { Not tested yet but, from return of experience, no foreseen } \\
\text { difference compared to result obtained on actuator line } \\
\text { alone (see Table 4) }\end{array}$ \\
\hline Optical quality & $14 \mathrm{~nm}$ rms WFE & $<20 \mathrm{~nm}$ rms WFE & $\begin{array}{l}\text { Value obtained from shape at rest measurement and out } \\
\text { filtering of spatial defects }>10 \text { mm (twice the inter- } \\
\text { actuator spacing) }\end{array}$ \\
\hline Hysteresis & NA* & $\begin{array}{l}\text { Not tested yet but, from return of experience, no foreseen } \\
\text { difference compared to result obtained on actuator line } \\
\text { alone (see Table 4) }\end{array}$ \\
\hline
\end{tabular}

*Value not available (NA) for present issue, will be communicated on a next paper.

To illustrate the results given in Table 6, we give on Figure 14, 15 and 16 some interferometric measurements, allowing a comparison with Figure 3, 4 and 5. 


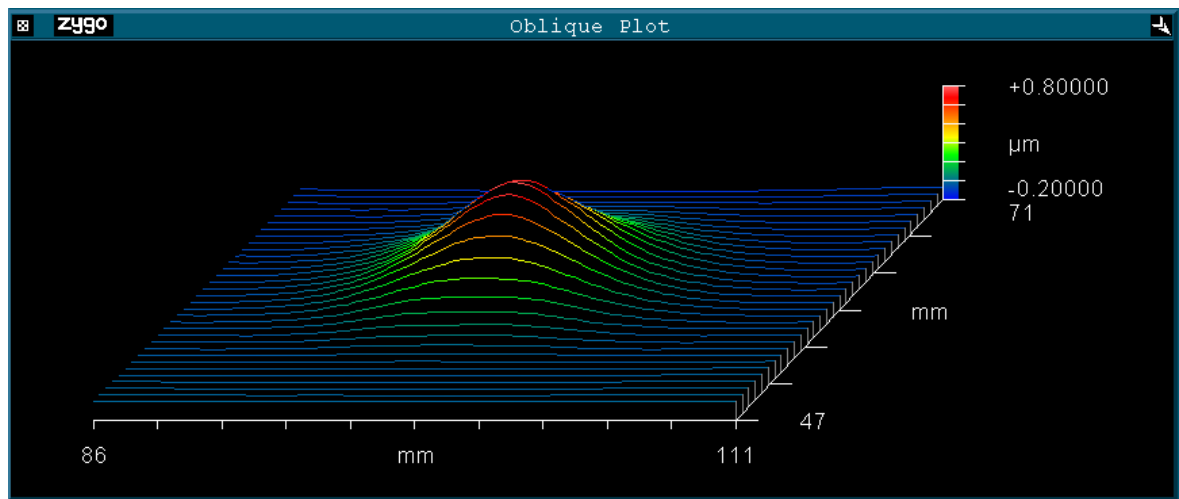

Figure 14. Measured single stroke of $0.9 \mu \mathrm{m}$ when one actuator is driven at $100 \mathrm{~V}$, leading to $3.5 \mu \mathrm{m}$ for $400 \mathrm{~V}$ (i.e. $7 \mu \mathrm{m}$ PV for $+/-400 \mathrm{~V}$ ).

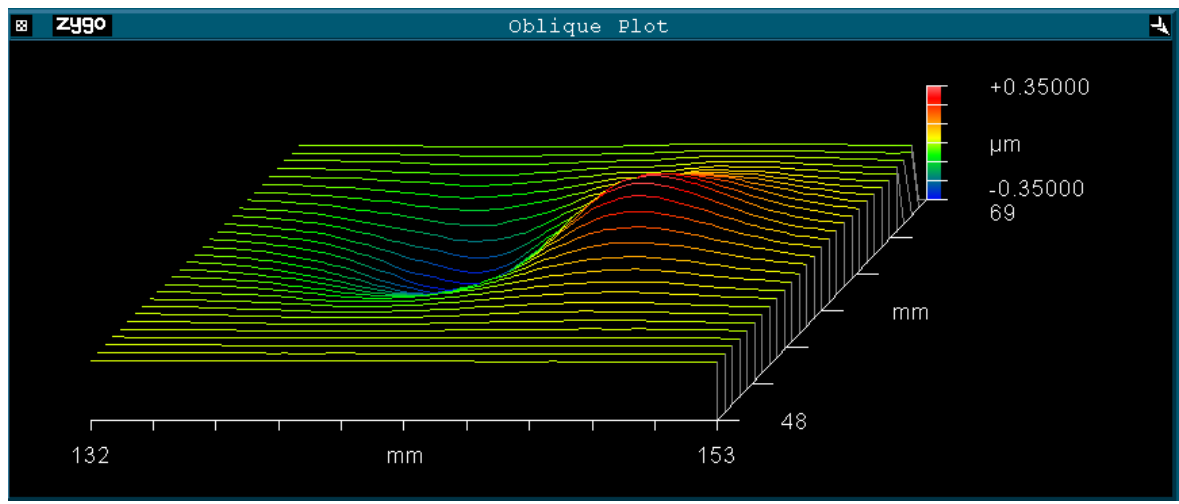

Figure 15. Measured inter-actuator stroke of $0.6 \mu \mathrm{m} \mathrm{PV}$ obtained when one actuator is driven at $+50 \mathrm{~V}$ and its neighbor at $-50 \mathrm{~V}$, leading to $4.8 \mu \mathrm{m}$ for $+/-400 \mathrm{~V}$.

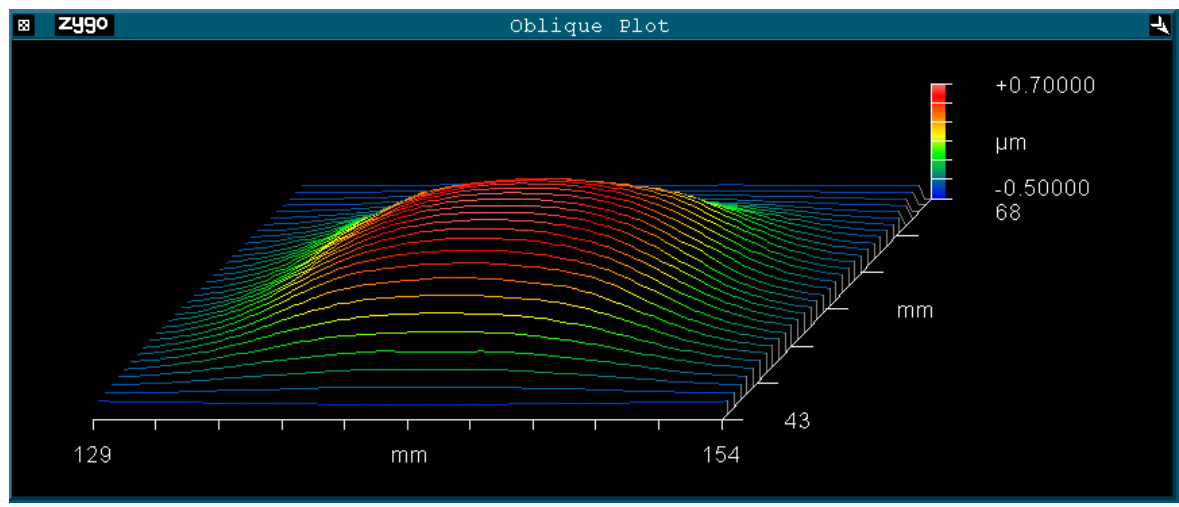

Figure 16. Measured maximum stroke of $1.0 \mu \mathrm{m}$ obtained when $3 \times 3$ actuators are driven at $50 \mathrm{~V}$, leading to $8.0 \mu \mathrm{m}$ for $400 \mathrm{~V}$ (i.e. $16 \mu \mathrm{m}$ PV for $+/-400 \mathrm{~V}$ ).

The optical quality has been obtained from shape at rest measurement and out filtering of spatial defects larger than $10 \mathrm{~mm}$, result is given on Figure 17. 


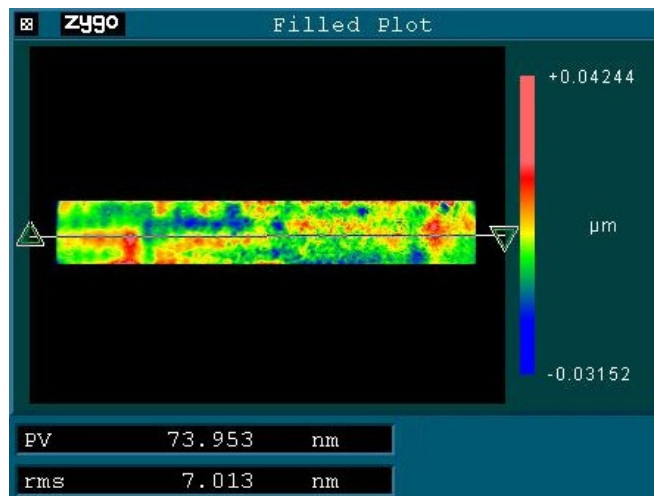

Figure 17. Best flat error estimate of $7 \mathrm{~nm}$ rms mechanical obtained from shape at rest measurement and out filtering of spatial defects larger than $10 \mathrm{~mm}$ (twice the inter-actuator spacing).

Besides, in order to overview the actuator uniformity, we have made a stitching of three measurements on $150 \mathrm{~mm}$ aperture, when the DP is driven in "waffle" mode. Result is given on Figure 18.

Figure 18. Stitching of three measurements on overall surface of DP, when waffle mode applied. The $6 \times 60$ actuators are clearly visible.

Finally, two of the main properties of a deformable mirror are shown on figure 19: reflection and ability to shape a wavefront!
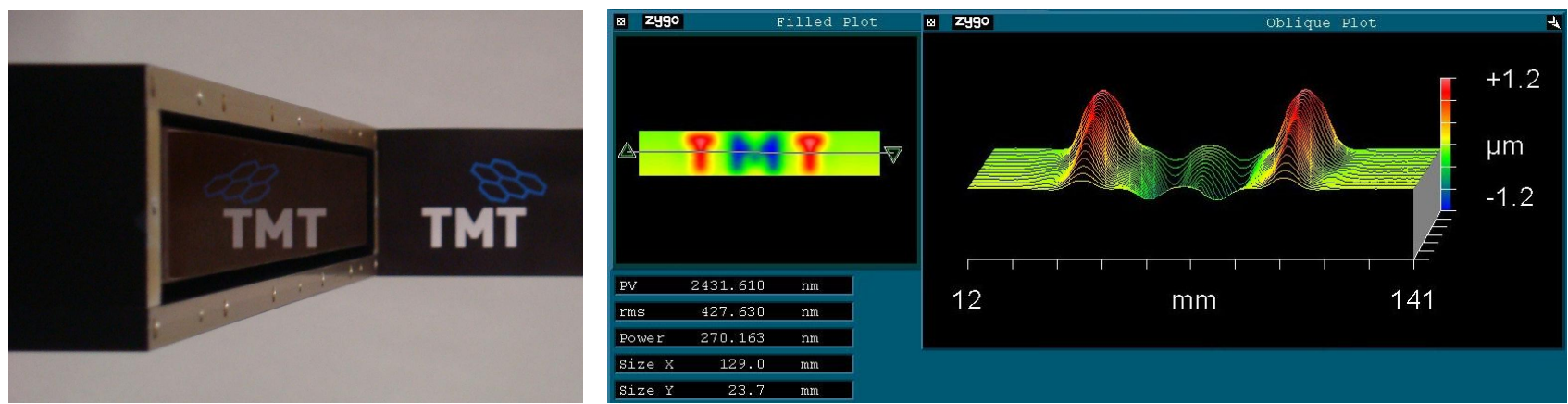

Figure 19. Photograph of the demonstration prototype (not coated) in grazing incidence (left) and actual interferometric measurement with very specific shape (right).

\section{Test at low temperature $\left(-30^{\circ} \mathrm{C}\right)$}

Test of the DP at $-30^{\circ} \mathrm{C}$ is the next step of present work and will be communicated on a next paper. 


\section{CONCLUSION}

We have completed the design and finite element analysis of the two NFIRAOS DMs and the demonstration prototype. This theoretical study showed that expected spatial (strokes, optical quality) and temporal (resonance frequency) performances are compliant with operational specifications. In addition, we have manufactured and tested a demonstration prototype. The test on actual actuators confirmed the theoretical functional results at low temperature as well as the expected reliability estimates.

\section{REFERENCES}

[1] Ellerbroek, B. et all, "The TMT Adaptive Optics Program," Presented at Adaptive Optics for Extremely Large Telescopes (AO4ELT2), Victoria, Canada (2011).

[2] Sinquin, J.-C., Bastard, A., Cousty, R., Guillemard, C., Morin, P., Pagès H., "Advancement of Piezo-Stack DM technology at CILAS: Example of HODM for KIS Gregor Solar Telescope," Presented at Adaptive Optics for Extremely Large Telescopes (AO4ELT2), Victoria, Canada (2011).

[3] Sinquin, J.-C., Guillemard, C., Bastard, A., Lagier, G., Morin, P., "Piezo Stack Array Deformable Mirrors and new associated technologies: Spherical Shape and Tip/Tilt Mount," Presented at OSA Conference "Adaptive Optics: Methods, Analysis and Applications," San Jose, California, USA (2009).

[4] Wang, L., "Analysis of the Flatness of CILAS DM FEA Model," TMT Technical Note (2011).

[5] European Committee for Electrotechnical Standardization, "European Standard on Rotating electrical machines," EN 60034, EU (2010).

[6] Ellerbroek, B. et all, "TMT adaptive optics program status report," Presented at the SPIE Conference on Astronomical Telescopes + Instrumentation, Amsterdam, The Netherlands (2012). 